\title{
Diclofenac Sensitivity to Vultures' Death and Environmental Pharmacology
} Syed Ziaur Rahman ${ }^{1}$, Ahmad Zee Fahem ${ }^{2}$

\begin{abstract}
:
Pharmacovigilance deals with the study of adverse drug reactions. It provides information from which to detect adverse update of drugs. The environmental impact of drugs is a rapidly evolving problem. Withdrawal of diclofenac from veterinary practice and various other such exampleshaving direct impact on the environment led to the development ofa newdiscipline which may be called as "pharmacoenvironmentology". Evaluation of the potential environment risks posed by the medical product is thus needed. This impact should be assessed, and on a case by case basis, special arrangements to limit it should be envisaged.

Keywords: Pharmacovigilance, pharmacoenvironmentology, diclofenac, vultures extinction.
\end{abstract}

International Journal of Human and Health Sciences Vol. 04 No. 01 January'20 Page : 19-25 DOI: http://dx.doi.org/10.31344/ijhhs.v4i1.115

\section{Introduction}

Environmental pharmacology is an emerging specialty of pharmacology. It is defined as the effect of pharmaceuticals and house care products on the environment and ecosystem. It involves the study of gene-environment, drug-environment and toxin-environment interaction, for which specific terminologies have been used very appropriately i.e. "ecogeneology", "ecopharmacology", and "ecotoxicology", respectively. ${ }^{1}$

"Ecopharmacology" (ecosystem + pharmacology) as a broader term encompasses the entry of both "pharmaceutics and personal care products (PPCPs)" as well as "industrial and chemical pollutants (IACPs)" into the environment by any route and at any concentration disturbing the balance of ecology (ecosystem). This impact of PPCPs and IACPs on environment cannot be a part of pharmacovigilance activity by virtue of its definition. ${ }^{2}$

"Pharmacovigilance is an activity to monitor, detect, assess, understand and prevent any obnoxious adverse drug reactions at therapeutic doses that appear in animal and human beings." The above definition of pharmacovigilance by WHO pertains to "therapeutic concentrations". However, this definition is not used in the European Union or United States where it also encompasses misuse, abuse, overdose, etc., as well as to the environmental effects (at therapeutic dosesor otherwise). The term 'pharmacoenvironmentology' deals with the impact of drugs on environment which are administered to humans and animals at therapeutic doses.

With the advancement in technology newer and more potent drugs are being synthesized and used on an ever-increasing scale. When a human or animal is given a drug, it may be well or poorly absorbed from the site of administration. Clearly, unabsorbed drug will pass with faeces into the environment. When a drug is administered to humans or animals it may be metabolized to variable extent and released into the environment as the parent drug or metabolites or a mixture of both. Once they are excreted into the environment (direct affection to the environment), they enter food chains and concentrate into larger predators (indirect affection to the human race).

If drugs for human as well as animal use regardless of whether the dose was therapeutic or otherwise enter the environment causing obnoxious reactions subsequent to pharmacotherapy via elimination from living organism, then this concept was defined in a specific domain of pharmacovigilance or more appropriately a part of environmental pharmacovigilance. ${ }^{3}$ This specific area is now referred as "pharmacoenvironmentology" in 2006. ${ }^{3}$

Diclofenac Induced Saga of Vulture Extinction in South Asia

The population of vultures across the Asian

1. Professor Syed Ziaur Rahman, Department of Pharmacology, Jawaharlal Nehru Medical College, Aligarh Muslim University, Aligarh 202002, India

2. Dr. Ahmad Zee Fahem, Department of Pharmacology, Jawaharlal Nehru Medical College, Aligarh Muslim University, Aligarh 202002, India

Correspondence to: Professor Syed Ziaur Rahman, Department of Pharmacology, Jawaharlal Nehru Medical College, Aligarh Muslim University, Aligarh 202002, India.E-mail: rahmansz@yahoo.com 
subcontinent have shown a rapid decline in the last few decades and are on the brink of extinction. Unintentional secondary poisoning of vultures that fed upon carcasses of diclofenac-treated livestock lead to decrease in populations in the Indian subcontinent. The population of vultures in India have declined by $99.9 \%$ during last 20 years. In South Asia millions of vultures have disappeared. Warnings have been issued regarding extinction of three species of Asian vultures within 10 years and the oriental white-backed vulture, has shown a decline of 99.9 per cent in its population since 1992. According to a study by the Bombay Natural History Society, the oriental white-backed vulture, once thought to be the commonest bird of prey in the world, has lost $99.9 \%$ of its population between 1992 and 2007. This is the fastest declining wild bird in the history, a demise which is more rapid than that of the "dodo". Numbers of long-billed and slender-billed vultures have together fallen by almost $97 \%$ in the same period. Populations of the white-rumped vulture, long-billed vulture and slender-billed vultures have declined by more than 90 percent between the years 1992 and 2000 . Currently, only 11,000 vultures survive in India. If it continues to decline at this rate, only around 6,000 vultures would be left and finally they may become extinct. ${ }^{4}$

Vultures also called "lords of the sky" have a very big role in the Asian ecosystem. They dispose carcasses that would otherwise lead to a significant health risk. Gyps vultures were widely distributed across Asia and Africa.

Gyps indicus found in Indian subcontinent is an Old World vulture of family Accipitridae.It also comprises eagles, kites, buzzards and hawks. Gyps indicus is closely related to the European Griffon vulture, G. fulvus. It breeds on crags or in trees in mountains of Pakistan and India. They form loose colonies. The population is mostly resident. The birds in the eastern part of the range were earlier considered a subspecies. Now they constitute a separate species calledslender-billed vulture Gyps tenuirostris. Previously, both were grouped together as long-billed vulture.

The long-billed vulture is a typical vulture, with a bald head, very broad wings and short tail feathers. It is smaller and less heavily-built than European Griffon, usually weighing between 5.5 and $6.3 \mathrm{~kg}$ (12-13.9 lbs) and measuring 80-100 cm (32-40 in) long and 205-229 cm (81-91 in) across the wings. It is distinguished from that species by its less buff body and wing coverts.

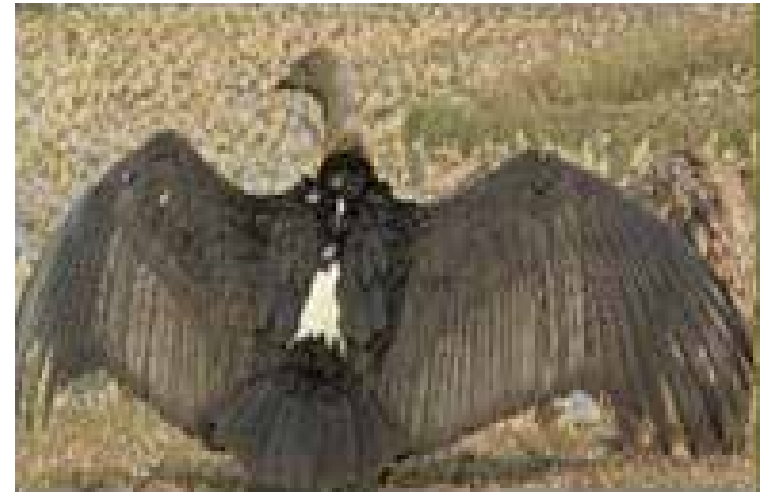

Oriental white-backed

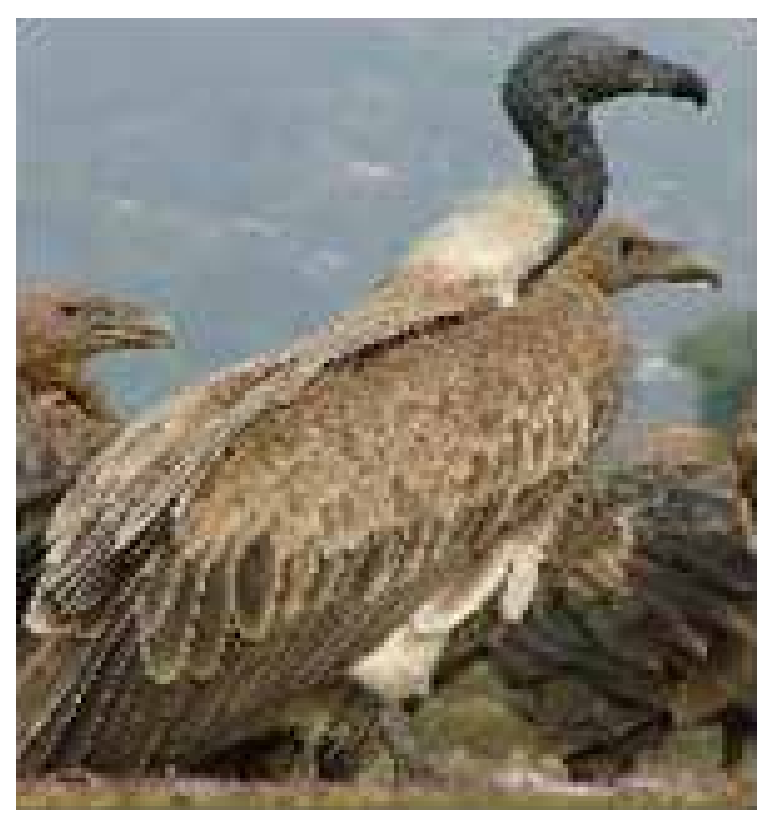

Slender-billed

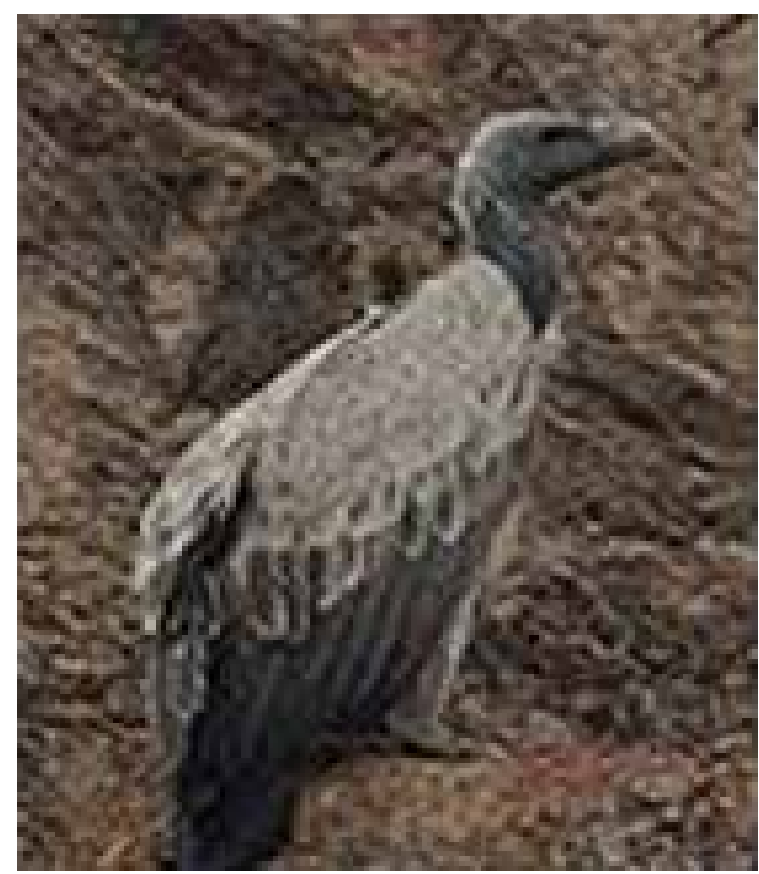

Long-billed 
International Journal of Human and Health Sciences Vol. 04 No. 01 January'20

In Asia three vulture species belonging to the genus Gyps are now critically endangered. These are the oriental white-backed vulture G. bengalensis, slender-billed vulture $G$. tenuirostris and long-billed vulture $G$. indicus. The loss hasled to massive impacton ecology and society.

The vultures on the Indian subcontinent disappeared very quickly. Alarms were first rung by wildlife conservation organization of India, Bombay Natural History Society (BNHS) in the late 1990s. Nesting pairs at Keoladeo National Park near Bharatpur, India decreased from 353 in $1987 / 88$ to 20 in 1998-99. No active nests were recorded at the park in either the 1999/2000 or the $2000 / 01$ season. Numbers of long-billed vultures also declined from 816 birds in 1985-86 to 25 in 1998-99, with only one bird seen in the 19992000 season. Studies reported large numbers of dead adult vultures (73 recorded in 1997/98), suggesting that the decline was related to an increase in mortality rate. ${ }^{5}$

The population size of oriental white-backed vultures declined by an estimated $97 \%$ at Keoladeo and in 2003 this colony was extinct. These declines were coupled with high mortality of all age classes. Since the initial surveys, it has been confirmed that these declines have occurred in all regions across India. Some birds appear sick and lethargic for a protracted period before death, often exhibiting a "neck drooping" posture, characteristic of a vulture that is weak and dehydrated.

In Pakistan, there was rapid decline in the counts of oriental white-backed vultures (Gyps bengalensis) and in other species. In one area, the decline in the oriental white-backed vulture has been in the range of $95 \%$ since the $1990 \mathrm{~s} .{ }^{5}$ There were findings of renal failure and visceral gout in the affected animals. It was correlated with findings of high concentrations of the non-steroidal antiinflammatory drug diclofenac, and the ability of diclofenac to reproduce the effects in the birds. It was proposed that the morbidity and mortality in the vultures was due to the animals scavenging on dead livestock which had been treated with diclofenac prior to death. Diclofenac is available as an over the counter veterinary drug in Indian subcontinent and is widely used. ${ }^{6}$ Attempts to model the toxic effects of diclofenac using domestic poultry have proved unsuccessful. ${ }^{7}$ Attempts are now being made to limit the availability of diclofenac. ${ }^{8}$ Drug Controller General of India has notified to ban the use of diclofenac as veterinary medicine in India.

\section{Causes of Extinction}

After a long interval of time it was possible to find the reason of the disappearanceof the vulture species in India. ${ }^{9}$ It was found that diclofenac, a non-steroidal anti-inflammatory drug (NSAID) is the reason for the vulture disappearance. ${ }^{10} \mathrm{After}$ eliminating the classic causes of renal failure, researchers tested the proposition that vultures were affected by a toxin while feeding on livestock carcasses (their main food source). Diclofenac, an analgesic is known to be toxic to the kidneys of mammals. In 2004, Peregrine Fund of USA investigating in Pakistan came to conclusion that diclofenac was responsible for decline in whiterumped vultures. Bombay Natural History Society, the UK's Royal Society for the Protection of Birds (RSPB), the Zoological Society of London and others extended this work to show diclofenac as the major cause of decline in South Asia. ${ }^{11,12}$

Diclofenac, is one of the most commonly used painkiller in veterinary practice. It was discovered that the use of diclofenac increased over the same time period as the decline in vultures. It was used to treat lameness and injury which are common ailments before the death of a buffalo or cow. When these animals die and are eaten by vultures, a single meal will be sufficient to kill the vultures. Experiments show that vultures are highly susceptible to diclofenac and are killed by feeding on the carcass of an animal soon after it has been treated with the normal veterinary dose. ${ }^{13}$

Diclofenac causing kidney damage leads to increase in serum uric acid levels, visceral gout and subsequent death. Acute necrosis of proximal convoluted tubules in these vultures was severe. Glomeruli, DCTs and collecting tubules were comparatively unaffected in the vultures with early lesions. In most vultures, however, lesions were extensive with large urate aggregates obscuring renal architecture. Inflammation was minimal. Excessive uric aciddeposition in the organ parenchyma and surface of the organs (visceral gout) was found in vultures with renal failure. Residue testing found diclofenac in all the analyzed vultures that had died with visceral gout. Vultures that had died of other causes (including trauma, gunshot and lead poisoning) tested negative for diclofenac residues. ${ }^{14}$

The vultures that have died in the decline showed kidney damage and uric acid crystals throughout their bodies, but no disease causing microbes or environmental toxins were detected. Vultures that died because of pesticide poisoning or collisions 
International Journal of Human and Health Sciences Vol. 04 No. 01 January'20

had no uric acid. Analysis of the kidneys from dead vultures with visceral gout has shown diclofenac residues, while no residues were found in other birds. A high proportion of vultures found dead or dying in India and Nepal also showed the presence of residues of diclofenac and visceral gout, a post-mortem finding such as at Indian Veterinary Research Institute (IVRI),Izzat Nagar (Bareilly, India) that is strongly associated with diclofenac contamination in both species.

Not much is known about the physiological effects of NSAIDs in birds. Diclofenac inhibits prostaglandins (PGs) formation in mammals. The mechanism by which diclofenac induces renal failure in vultures can be through the inhibition of the modulating effect of prostaglandin on angiotensin II-mediated adrenergic stimulation. Renal portal valves open up in response to adrenergic stimulation which redirects portal blood to the caudal vena cava and bypasses the kidneys. If diclofenac removes a modulating effect of prostaglandins on the renal portal valves, indiscriminant activation of these valves would redirect the primary nutrient blood supply away from the renal cortex. This would result in ischemic necrosis of the cortical proximal convoluted tubules. ${ }^{15}$

The researchers also gave diclofenac, and meat from animals treated with diclofenac, to nonreleasable vultures rescued from nesting colonies. These vultures also died by consuming diclofenac in very small doses, with the same symptoms as the dead, wild vultures. With increase in the dose of the drug, the probability of death increased several folds. Vultures travel large distances to feed on a carcass, so each one gets a small bit of many animals. As few as one in 250 carcasses containing diclofenac at a dose lethal to vultures, would be sufficient to cause the observed decline in vulture numbers (30\% per year). So even small-scale use of the drug can have catastrophic consequences.

Diclofenac was found to be lethal to vultures at $10 \%$ of the therapeutic mammalian dose. Tissue residues in livestock treated at the labeled dose rate were sufficient to cause gout and death in vultures. These findings, coupled with the high incidence of visceral gout in wild vultures found dead in Pakistan, India and Nepal confirm that diclofenac is the primary cause of the Asian vulture decline. Analyses indicate that the level of diclofenac contamination found in carcasses of domesticated ungulates in 2004-2005 was sufficient to account for the observed rapid decline of the oriental white-backed vulture in India.

Diclofenac is an anti-inflammatory and analgesic. The name is derived from its chemical name: 2-(2, 6-dichloranilino) phenylacetic acid. In the United Kingdom, India, and the United States, it is supplied as either the sodium or potassium salt, in China most often as the sodium salt, while in some other countries only as the potassium salt. Diclofenac is available as a generic drug in various formulations. Over the counter (OTC) use is approved in some countries for minor problems. Treatment with other NSAIDs like ibuprofen and phenylbutazone also led to death in vultures. NSAID toxicity was found in species also like raptors, storks, cranes and owls.So the potential conservation impact of NSAIDs may extend beyond Gyps vultures and will be significant for New World vultures. Diclofenac is widely across the globe and presents a risk to Gyps species from other regions too.

\section{Adverse Consequences}

While the extinction of vultures may not strike the same cord as other cuter creatures, they play a vital role in the Asian ecosystem. Vultures are very important species and their decline is adversely affecting the ecosystem. This imposes a heightened risk of diseases that threaten human life and welfare.

In India, vultures dispose carcasses thereby reducing the risk of disease. With decline in vultures, carcasses stay much longer posing enhanced risk to health. The massive vulture disappearances had terrible consequences throughout India. ${ }^{16}$ With no vultures to eat cattle carcasses (which are just dumped when the cows die), other predators have filled the gap. Feral dogs are filling the scavenging gap, and their growing numbers also pose increased risks to human health and safety. Since they are carriers of rabies.

Populations of feral dogs have increased massively in recent past with an increase of millions of more dogs to the streets. As per a report published in the journal Ecological Economics suggests this tremendous increase in feral dogs has led to dramatic increase in attacks on humans numbering in millions and caused atleast 47,300 human deaths from rabies. Indian experts have recorded a sharp rise in the number of feral dogs as they fill the gap in the food chain, and with that an increase in the number of cases of rabies and other diseases. The population of rats have also increased, and that's always a harbinger of diseases to come. ${ }^{4}$ 


\section{Strategies to Check Extinction}

Stopping and reversing the decline in the population of vultures is one of the most urgent conservation priorities. The solution to this problem requires commitment by governments and pharmaceutical industry. As per conservationists, the birds can only be saved by banning the use of diclofenac and setting up a network of captive breeding centers. ${ }^{17}$ Although, manufacture of the drug has been outlawed in India since 2006 however it remains easily available.Farmers and vets resorted to the use of human form of diclofenac although an effective and safer alternative is available. Measures to make diclofenac less readily available to use are important in saving these birds. Steps to make meloxicam, which is equally effective to make it more widely available are just as important.

Vulture populations are already at critically low levels. In 2006, the Drug Controller General (India) withdrew all licenses granted for the manufacture of diclofenac for veterinary use within India. Although the Indian Government banned the veterinary use of diclofenac, this obviously needs to be implemented and properly enforced before vulture numbers can even start to recover. Diclofenac was also banned in Pakistan and Nepal in 2006, after Indian Government's initiative.

\section{Meloxicam - The Diclofenac Replacement}

The drug meloxicam is safer for the vultures at the likely range of levels they would be exposed to in the wild. The Drug Controller General of India had issued a directive to phase out veterinary diclofenac and replace it with meloxicam. Meloxicam, which is similar to diclofenac in its effectiveness for treating livestock, has recently become available for veterinary use in India and could easily be used in place of diclofenac. This recommendation was based on extensive acute safety studies in the African white-backed vulture (Gyps africanus), which evaluated worst case scenarios of maximum intake based on a once in three day feeding pattern. No mortality was detected with meloxicam, which was administered to over 700 birds from 60 species. The relative safety of meloxicam supported by a number of studies indicates the suitability of this NSAID to replace diclofenac in Asia. Aceclofenac in caltle is metabolized into diclofenac, which will again harm the vultures. ${ }^{18}$

Environmental Risk Assessment for Diclofenac

Many models were proposed to screen the effect of PPCPs in aquatic and terrestrial environment. ${ }^{19,20}$ Uptake and Biological Effects of Environmentally Relevant Concentrations of the Nonsteroidal Anti-inflammatory Pharmaceutical Diclofenac in Rainbow Trout (Oncorhynchus mykiss) is thoroughly studied by Mehinto. ${ }^{21}$

Preclinical safety testing has not been well established for avian species unlike for mammalian and environmental toxicity, Hasan Izet al. ${ }^{22}$ put forward a question if there was a preclinical model that could have predicted the toxic effect of the drug. To test the acute toxic potential of pesticides in birds under Organization for Economic Cooperation and Development (OECD) guidelines (guideline 223), three avian species were exposed to the drug. Exposed Japanese quails (Coturnix japonica) and Muscovy ducks (Cairina moschata) had shown similar clinical signs and pathology to those previously reported in vultures i.e. hyperuricemia, depression, death, visceral gout and nephrosis. However, exposed domestic pigeons (Columba livia domestica) were insensitive. Following a pharmacokinetic analysis, the drug was well absorbed and distributed in the pigeons with a half-life below $6 \mathrm{~h}$. A toxicokinetic evaluation in quails showed poisoning was due to metabolic constraint, with a half-life and mean residence time above $6 \mathrm{~h}$ and $8 \mathrm{~h}$ respectively resulting in death. Toxicity seen in the ducks was however not related to metabolic constraint but hyperuricemia as metabolism was rapid [half-life (1-2h) and mean residence time (2-3h)] irrespective of survival or death. Despite succumbing to diclofenac, the established oral median lethal dose $\left(\mathrm{LD}_{50}\right)$ of $405.42 \mathrm{mg} /$ $\mathrm{kg}$ and $189.92 \mathrm{mg} / \mathrm{kg}$ in Japanese quails and Muscovy ducks respectively from this study were substantially higher than those reported for Gyps vultures $(0.098 \mathrm{mg} / \mathrm{kg})$ which is as a result of the rapid elimination of the drug from the body in the former species. More importantly, it suggests that these species are not suitable as surrogates for nonsteroidal anti-inflammatory drug toxicity testing and that the toxicity of diclofenac in vultures is idiosyncratic most likely as a result of species specific metabolism. ${ }^{22}$

\section{Captive Vulture Breeding Program}

Captive breeding program is the most important tool in the fight against the extinction of vultures. Three captive breeding centers housing the three species under impending extinction have been built across India. One is in Harayana housing 120 vultures, the second in West Bengal holds 52 vultures and the third in Assam holds 10 
vultures. Few other centers have been built in south Asian countries like Nepal and Pakistan. These centers aim to hold viable populations of all three species. The Vulture Care Centerat Pinjore, Haryana, operated by the Bombay Natural History Society now holds good numbers of Indian and white-rumped vultures, and received its first slender-billed vultures in early 2006. A further center to house slender-billed vultures at Rajabhatkhawa, outside the Buxa Tiger Reserve in West Bengal, has also now been completed, receiving its first occupants in early 2006. Other centers, in association with Zoological Society of London (ZSL) and WWF-Pakistan are planned in Nepal and Pakistan, respectively.

Conservationists intend to take vultures into captivity to maintain breeding populations. These will be released back into the natural habitat when populations are breeding and the environment is effectively free of diclofenac.

A study of 11 of Nepal's 75 administrative districts by Bird Conservation Nepal (BCN, BirdLife in Nepal) finds that the use of diclofenac has dropped by 90 per cent since 2006 . The work by BCN and its partners, notably the Nepalese government (Department of Drug Administrative and Department of National Parks and Wildlife Conservation) is worth to be appreciable in this direction. $\mathrm{BCN}$ is working collaboratively for a complete phasing out of diclofenac and other harmful NSAIDdrugs from the market. Support has come not only from conservation organizations such as the Royal Society for the Protection of Birds (RSPB) (Birdlife in the UK), ZSL and WWF, but also from local veterinary and para-veterinary practitioners, local pharmacists, pharmaceuticals distributors associations and local communities. In ten districts of western Nepal including Chitwan, BCN has replaced half a million rupees $(\$ 8,000)$ worth of diclofenac with the safe and equally effective alternative drug, meloxicam. In Nepal eatery hasbeen opened for the scavengers. It is in the Nawalparasi district in southwest Nepal. The niche 'restaurant' has been operating for a little over a year. Since then, the population of the vultures has almost doubled in the region. What is special about the restaurant is that it ensures the birds get food that is free of diclofenac. A number of volunteers and two fulltime employees working for the eatery collect sick cows and care for them till they die. Then they physically cart them to the open field that serves as the restaurant for these birds. In collaboration with a number of government and non-governmental agencies, over the last five years $\mathrm{BCN}$ has also conducted a massive conservation-awareness program throughout Nepal, highlighting the importance of vultures in maintaining balanced ecosystems.

There are early indications that the mortality of the vulture population has been reduced but not stopped. Chris Bowden, the RSPB's vultureprogram manager, said, "The Indian government is to be congratulated on taking this huge step that we have working towards ever since the discovery that diclofenac was such an acute problem."

All said and done, and inspite of the introduction of safer drug meloxicam, diclofenac is still in use in India and Nepal. ${ }^{23}$ At the Rani vulture breeding and conservation site in Guwahati (India), for instance, the population of Gyp vultures is fast disappearing. Field workers and researchers on the ground attribute it to the use of diclofenac. Wildlife enthusiasts are launching aggressive campaigns to enforce the ban on the use of diclofenac still widely available in India. Other groups are focusing on providing safe food for vultures. They do look ugly, but they are certainly essential for the hygiene of our community.

Acknowledgement: We thank the Centerfor Safety and Rational Use of Indian Systems of Medicine (CSRUISM), Ibn Sīnā Academy of Medieval Medicine andSciences (IAMMS), Aligarh, India, for providing resource materials in writing the above paper.

Contribution of authors: All authors contributed equally

Conflict of interest:There are no conflicts of interest. 


\section{References:}

1. Banjoko B. Environmental Pharmacology - An Overview. In: Pharmacology and Therapeutics. InTech. 2014.

2. Rahman SZ, Khan RA, Kumar V, Misbahuddin M. Pharmacoenvironmentology - A Component of Pharmacovigilance.BMC Environmental Health. 2007;6:20.

3. Rahman SZ.Impact of Human Medicines on Environment - A New Emerging Problem.Population Envis. 2006;3(2):3-4.

4. Badyal D. Drug Induced Saga of Vulture Extinction in India. In: Rahman SZ, Shahid M \& Gupta V.An Introduction to Environmental Pharmacology. Ibn Sina Academy, Aligarh, India. 2008;pp. 177-86.

5. V Prakash. Status of vultures in Keoladeo National Park, Bharatpur, Rajasthan with special reference to population crash in Gyps species.J Bombay Natural History Society. 1999;96:365-78.

6. Oaks JL, Gilbert M, Virani MZ, Watson RT, Meteyer $\mathrm{CU}$, Rideout BA. Diclofenac residues as the cause of vulture population decline in Pakistan.Nature. 2004;427:630-3.

7. Naidoo V, Duncan, Bekker L, Swan G. Validating the domestic fowl as a model to investigate the pathophysiology of diclofenac in Gyps vultures. Environmental Toxicology and Pharmacology. 2007;24 (3):260-6.

8. Anonymous. Pharmaceuticals in environment. Health Effects Review; An official journal of Department of Environmental Health, Boston University School of Public Health. 2002; pp. 1-3.

9. Hussain I, Khan MZ, Khan A, Javed I \& Saleemi MK. Toxicological effects of diclofenac in four avian species. Avian Pathology. 2008;37(3):315-21.

10. Press Information Bureau, Government of India. Saving vultures from extinction, press release. (2005-05-16). ～(http://pib.nic.in/release/release. asp?relid=9303. Retrieved on 2006-05-12).

11. Green RE, Newton I, Shultz S, Andrew A. Cunningham, Gilbert M, Deborah J. Pain et al. Diclofenac poisoning as a cause of vulture population declines across the Indian subcontinent. Journal of Applied Ecology. 2004;41,793-800.

12. Green RE, Taggart MA, Senacha KR, Raghavan B, Pain DJ, Jhala Y et al. Rate of decline of the oriental white-backed vulture population in India estimated from a survey of diclofenac residues in carcasses of ungulates. Biol Lett. 2007;3:90-3.

13. Taggart MA, Senacha KR, Green RE, Jhala YV,
Raghavan B, Rahmani AR. Diclofenac residues in carcasses of domestic ungulates available to vultures in India.PLoS Biol. 2006;4:e66.

14. Cuthbert R, Parry-Jones J, Green RE, Pain DJ. NSAIDs and scavenging birds: potential impacts beyond Asia's critically endangered vultures. Environ Int. 2007;33:759-65.

15. Meteyer CU, Rideout BA, Gilbert M, Shivaprasad HL, Oaks JL. Pathology and proposed pathophysiology of diclofenac poisoning in freeliving and experimentally exposed oriental whitebacked vultures (Gyps bengalensis).Proc Biol Sci. 2004;271(6):S458-60.

16. Taggart MA, Cuthbert R, Das D, Sashikumar C, Pain DJ, Green RE et al. Diclofenac disposition in Indian cow and goat with reference to Gyps vulture population declines. Environmental Pollution. 2007;147(1):60-5.

17. Swan G, Naidoo V, Cuthbert R, Green RE, Pain DJ, Swarup D. Removing the threat of diclofenac to critically endangered Asian vultures.J Wildl Dis. 2005;41:707-16.

18. Galligan, TH, Taggart, MA, Cuthbert, RJ, Svobodova $\mathrm{D}$, Chipangura J, Alderson et al. Metabolism of aceclofenac in cattle to vulture-killing diclofenac. Conservation Biology. 2016;30:1122-7.

19. Rahman SZ. Need of Designing Model for Screening of PPCPs (Ecopharmacology) and Therapeutic Drugs (Pharmacoenvironmentology) in Aquatic and Terrestrial Environment. IABCR.2018;4(3):100-5.

20. Naidoo V, Wolter K, Cromarty AD, Bartels P, Bekker $\mathrm{L}, \mathrm{McGaw} \mathrm{L}$. The pharmacokinetics of meloxicam in vultures. PLoSONE. 2007;2:e686.

21. Mehinto AC, Hill EM, and Tyler CR. Uptake and Biological Effects of Environmentally Relevant Concentrations of the Nonsteroidal Antiinflammatory Pharmaceutical Diclofenac in Rainbow Trout (Oncorhynchus mykiss). Environmental Science \& Technology. 2010;44(6),2176-82.

22. Hassan IZ, Duncan N, Adawaren EO, Naidoo V. Could the environmental toxicity of diclofenac in vultures been predictable if preclinical testing methodology were applied? Environ Toxicol Pharmacol. 2018;64:181-6.

23. Cuthbert RJ, Taggart MA, Saini M, Sharma A, Das A, Kulkarni MDet al. Continuing mortality of vultures in India associated with illegal veterinary use of diclofenac and a potential threat from nimesulide. Oryx. 2016;50(1):104-12. 